\title{
Detection of colistin resistant Klebsiella pneumonia co-producing extended spectrum, AmpC beta lactamase and carbapenemase in a tertiary hospital in Nigeria
}

\author{
I Yusuf 1,2, SM Qabli ${ }^{1}$, AM Magashi², Al Balarabe², A Kabir ${ }^{2}$, MR Kabir ${ }^{2}$, ES Olivia ${ }^{3}$, R Abbas $^{4}$ \\ From 3rd International Conference on Prevention and Infection Control (ICPIC 2015) \\ Geneva, Switzerland. 16-19 June 2015
}

\section{Introduction}

From 2011 to date, there are increasing detections of carbapenem resistant Klebsiella pneumoniae (CRKP) in a 700 bed capacity general hospital in Kano, Nigeria. CRPK infections are very difficult to treat. Colistin is one of reserved antibiotics for treating CRPKs. Of recent, invitro colistin resistant strains of CRKP were detected by disc diffusion method using $10 \mu \mathrm{g}$ colistin discs (Oxoid, UK) according to the CLSI guidelines.

\section{Objectives}

To test the susceptibility of CRKP invitro to colistin and screen the colistin resistant isolates for extended spectrum beta-lactamase (ESBL), AmpC and Metallo beta lactamase (MBL) production.

\section{Methods}

Susceptibility of 34 CRPK to colistin was determined using disc diffusion method. Colistin resistant strains were concurrently screened phenotypically for ESBL and MBL according to CLS1 2012 breakpoints using double disk synergy test and modified Hodge test respectively. AmpC was detected using AmpC disk test.

\section{Results}

Result shows that 6 out of 34 CRPKs (17.6\%) were resistant to colistin (Interpretative criteria: resistant $\leq 11 \mathrm{~mm}$ ). Five CRPK produced ESBL and AmpC, and 3 produced MBL type of carbapenemase. Co-production of ESBL and AmpC was detected in 4 of the isolates, ESBL and MBL in 3,
AmpC and MBL in 2. ESBL, AmpC and MBLs were detected concurrently in 3 CRPK. Five out of the 6 CRKP $(83.3 \%)$ were isolated from urine and cathertips, while the remaining one was from wound.

\section{Conclusion}

The study indicates that, colistin resistant CRPK strains have emerged in the hospital. Co-production of two or three of the beta lactamase enzymes by many of the isolates is worrisome, since it further narrow down treatment options.

\section{Disclosure of interest}

None declared.

\section{Authors' details}

'Microbiology Unit, King Abdulaziz University, Jeddah, Saudi Arabia. ${ }^{2}$ Microbiology, Bayero University Kano, Nigeria, Kano, Nigeria. ${ }^{3}$ Microbiology, Delta State University, Abraka, Nigeria. ${ }^{4}$ Microbiology, Bayero University, Kano, Kano, Nigeria.

Published: 16 June 2015

Reference

1. Clinical Laboratory Standards Institute: Performance Standards for Antimicrobial Susceptibility Testing: Twenty-third Informational Supplement M100-S22. Wayne, PA, USA: CLSI; 2012.

doi:10.1186/2047-2994-4-S1-P129

Cite this article as: Yusuf et al:: Detection of colistin resistant Klebsiella pneumonia co-producing extended spectrum, AmpC beta lactamase and carbapenemase in a tertiary hospital in Nigeria. Antimicrobial Resistance and Infection Control 2015 4(Suppl 1):P129. 